\title{
Elastic properties of the titanium alloy Ti-6Al-4V
}

\author{
E. A. Trofimov ${ }^{\dagger}$, R. Ya. Lutfullin, R. M. Kashaev \\ †trofimovea12@gmail.com
}

Institute for Metals Superplasticity Problems RAS, 39 Khalturin St., 450001, Ufa, Russia

\begin{abstract}
The manuscript presents the results of the measurements of Young's modulus (E) for the two-phase titanium alloy Ti-6Al-4V. The estimation of $\mathrm{E}$ was made using two independent methods: standard mechanical tests (tensile test) on an Instron electronic dynamometer and the method of nanoindentation using a Nanoscan3D nanohardness-testing scanning machine. The elastic properties were studied for different structural states of the titanium alloy Ti-6Al-4V: nanostructured (NS), microcrystalline (MC) and coarse-grained (CG). The elastic moduli for $\alpha$ - and $\beta$-phases were measured by means of the nanoindentation method. It is shown that the value of $\mathrm{E}$ for the Ti-6Al-4V alloy in the CG state is smaller than in the NS state by more than $20 \%$, which is likely to be attributed to a change in the amount ratio between $\alpha$ - and $\beta$-phases characterized by different elastic properties.
\end{abstract}

Keywords: titanium alloy Ti-6Al-4V, Young's modulus of elasticity, nanostructure, nanoindentation, $\alpha$ - and $\beta$-phases

\section{Introduction}

The structural sensitivity of the elasticity modulus for the two-phase titanium alloy $\mathrm{Ti}-6 \mathrm{Al}-4 \mathrm{~V}$ has been insufficiently explored until the present time. Meanwhile, there is a widespread opinion that Young's modulus (E) is the structural insensitivity of metals $[1,2]$. In this context, this issue requires an actual detailed study, in particular with regard to the structural titanium alloy $\mathrm{Ti}-6 \mathrm{Al}-4 \mathrm{~V}$ in its different structural states.

According to the current concepts, promising for the use as a structural material in aeronautical engineering are nanostructured alloys, in particular, the titanium alloy Ti-6Al-4V [3-8]. Nanostructured semi-products from the two-phase $\mathrm{Ti}-6 \mathrm{Al}-4 \mathrm{~V}$ alloy exhibit increased static and cyclic strength and higher wear resistance. Contrariwise, it is well known that in single-phase nanostructured alloys the modulus of elasticity is noticeably reduced [9-10].

The aim of the our work is to carry out experiments for an estimation, by independent methods, of the normal Young's modulus (E) for the two-phase titanium alloy Ti-6Al-4V in different structural states and a divided estimation of $\mathrm{E}$ for each phase in the equilibrium state of the titanium alloy Ti-6Al-4V after annealing.

\section{Material and experimental procedure}

The object of study is the two-phase $\alpha+\beta$ titanium alloy Ti$6 \mathrm{Al}-4 \mathrm{~V}$ in the nanostructured (NS), microcrystalline (MC) and coarse-grained (CG) states. The chemical composition of the alloy completely corresponds to GOST 19807-91, as the Russian alloy VT6. The $(\alpha+\beta) \rightarrow \beta$ transformation temperature was $1253 \mathrm{~K}$ for the two-phase Ti-6Al-4V alloy used in our study.

For the initial sample, the alloy in the NS state was taken, produced by multiple isothermal forging at a temperature of $873 \mathrm{~K} \mathrm{[3]} \mathrm{followed} \mathrm{by} \mathrm{isothermal} \mathrm{rolling} \mathrm{at} \mathrm{a} \mathrm{temperature} \mathrm{of}$ $823 \mathrm{~K}$. The average grain size (d) of the NS state was $0.18 \mu \mathrm{m}$. The MC and CG states was obtained by vacuum annealing of the NS state at a temperature of $\mathrm{T}=1173 \mathrm{~K}$ ( 1 hour) and $\mathrm{T}=263 \mathrm{~K}$ ( 0.5 hours), respectively, the average grain size in the MC state was $5 \mu \mathrm{m}$ and in the CG state $103 \mu \mathrm{m}$ ( $\beta$-transformed grain). Also, a low-temperature annealing was performed on the NS sample at $\mathrm{T}=773 \mathrm{~K}$ ( 1 hour) for the internal stress relaxation of the initial NS alloy. At the same time, a slight growth of grains to an average of $0.21 \mu \mathrm{m}$ was observed.

Young's modulus E was determined by two independent methods. Mechanical tensile tests were carried out on an Instron electronic dynamometer in accordance with GOST $11701-84$ on flat samples with dimensions of the gage portions $130 \times 12.5 \times 0.75 \mathrm{~mm}^{3}$, the tension speed was $2 \mathrm{~mm} / \mathrm{min}$. Elastic deformation was measured using an extensometer with a base of $100 \mathrm{~mm}$. The tension was performed at room temperature. Another method - determination of hardness and elastic modulus by indentation - is adapted for determining the mechanical properties at the micro- and nano-level [11]. An experiment to determine Young's modulus for each phase was integrally performed with a NanoScan-3D scanning nanohardness tester on the electro-polished CG samples with a size of $12 \times 10 \times 0.75 \mathrm{~mm}^{3}$ produced from the NS alloy annealed in a vacuum at a temperature of $1263 \mathrm{~K}$.

Structural investigations were carried out on scanning (SEM) and transmission (TEM) electron microscopes JEM - 840 and JEM - 2000EX, respectively. Estimation of the phase composition of the Ti-6Al-4V alloy was 


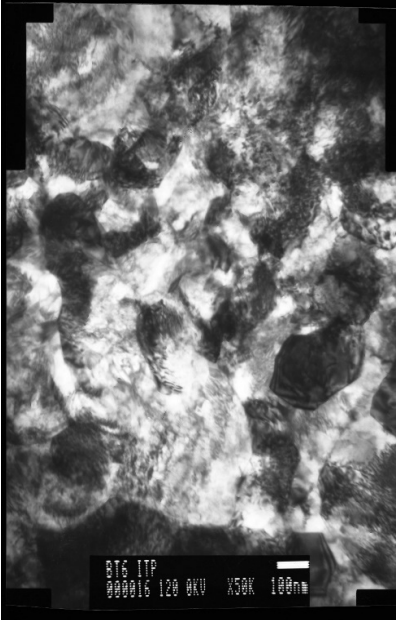

a

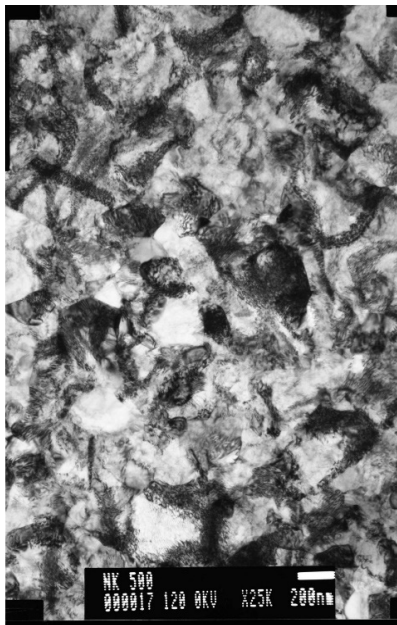

$\mathrm{b}$

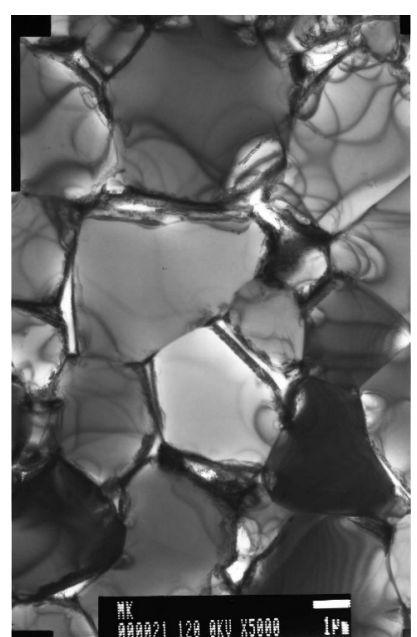

C

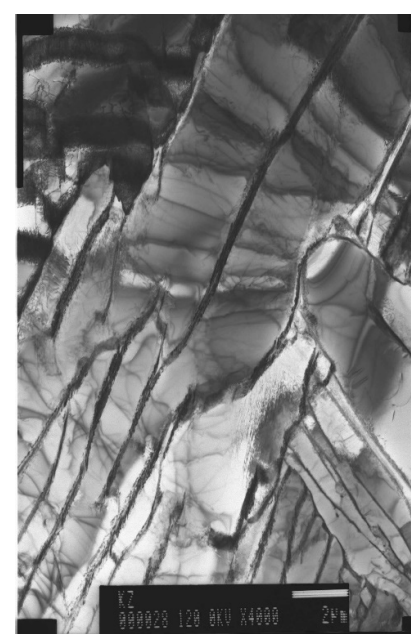

$\mathrm{d}$

Fig. 1. The structural states of Ti $-6 \mathrm{Al} 4 \mathrm{~V}$ alloy: $\mathrm{a}$ - initial NS state $(\mathrm{d}=0.18 \mu \mathrm{m}) ; \mathrm{b}-\mathrm{NS}$ state after low annealing at $\mathrm{T}=773 \mathrm{~K}(\mathrm{~d}=0.21 \mu \mathrm{m})$; c - MC state $(\mathrm{d}=5 \mu \mathrm{m})$; $\mathrm{d}$ - CG state $(\mathrm{d}=103 \mu \mathrm{m})$.

performed by X-ray analysis on a DRON-3 diffractometer. The diffractometer was operated in the following mode: voltage $-40 \mathrm{kV}$, current $-30 \mathrm{~mA}$, radiation $-\mathrm{Cu}$. The processing results were evaluated with help of the $X$-Ray program.

\section{Results and discussion}

The fine structure of the investigated alloy Ti- $6 \mathrm{Al}-4 \mathrm{~V}$ in different structural states, taken on a transmission electron microscope is shown in Fig.1. The alloy in the initial NS state (Fig.1a) has a high internal stress as evidenced by the presence of extinction contours. The NS state obtained after low-temperature annealing at $\mathrm{T}=773 \mathrm{~K}$ (Fig.1b) demonstrates a partial relaxation of internal stresses. In the MC state (Fig.1c) the structure consists mainly of the primary $\alpha$-phase and slightly of $\beta$-phase separation. The CG state (Fig.1d) shows a lamellar structure, where in the matrix the $\alpha$-phase stands out with the $\beta$-phase plates between the $\alpha$-phase.

According to the results of $X$-ray analysis, the phase composition of the investigated titanium alloy Ti-6Al-4V was determined (Fig.2). In the initial NS state the content of the $\alpha$-phase is maximum, low-temperature annealing at a temperature of $\mathrm{T}=772 \mathrm{~K}$ has almost no effect on the change in the volume ratio of the $\alpha$-phase and the $\beta$-phase in the alloy. Thus, the initial NS and low-temperature annealed

Table 1. The values of the normal elastic modulus E for the Ti-6Al-4V alloy obtained from the results of measurements using Instron and NanoScan - 3D

\begin{tabular}{|c|c|c|}
\hline Grain size, $\mu \mathrm{m}$ & $\mathrm{E}_{\text {ins }}, \mathrm{GPa}$ & $\mathrm{E}_{\text {nsc }}, \mathrm{GPa}$ \\
\hline 0.18 & 117.4 & 117.3 \\
\hline 0.21 & 107.8 & 116.7 \\
\hline 5 & 106.4 & 109.2 \\
\hline 103 & 95 & 89.4 \\
\hline
\end{tabular}

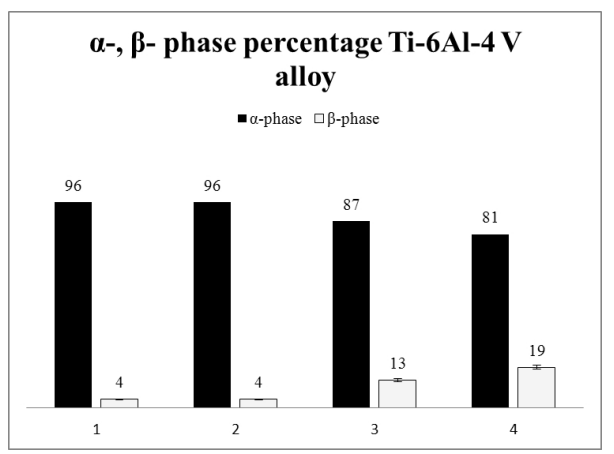

Fig. 2. Phase percentage distribution for each structural state: 1 $(\mathrm{d}=0.18 \mu \mathrm{m}) ; 2-(\mathrm{d}=0.21 \mu \mathrm{m}) ; 3-(\mathrm{d}=5 \mu \mathrm{m}) ; 4-(\mathrm{d}=103 \mu \mathrm{m})$.

states have the identical quantitative phase ratio. Annealing of alloy in the initial NS state at $\mathrm{T}=173 \mathrm{~K}$ for one hour is followed by an increase in the quantity of the $\beta$-phase, and consequently, a reduction in the quantity of the $\alpha$-phase. After annealing of the alloy at $\mathrm{T}_{\mathrm{pt}}=1253 \mathrm{~K}$ for half an hour, one can see an even greater increase in the quantity of the $\beta$-phase.

Table 1 shows the values of the elastic modulus of the titanium alloy Ti-6Al-4V in different structural states. The modulus of elasticity was determined from the results of mechanical tensile tests performed on an Instron electronic dynamometer, marked as $\mathrm{E}_{\text {ins }}$, as well as by indentation on the NanoScan-3D scanning nanohardness testing machine, designated as $\mathrm{E}_{\text {nsc }}$. The value of the normal modulus of elasticity of the investigated titanium alloy Ti-6Al-4V after the transition from the NS to CG states has decreased by more than $20 \%$. One possible reason for this non-trivial

Table 2. The modulus of elasticity E for the $\alpha$ - and $\beta$-phases in the Ti-6Al-4V alloy (CG state)

\begin{tabular}{|c|c|}
\hline Phase & E, GPa \\
\hline$\alpha$ & $92.8 \pm 10.6$ \\
\hline$\beta$ & $75.8 \pm 12.9$ \\
\hline
\end{tabular}




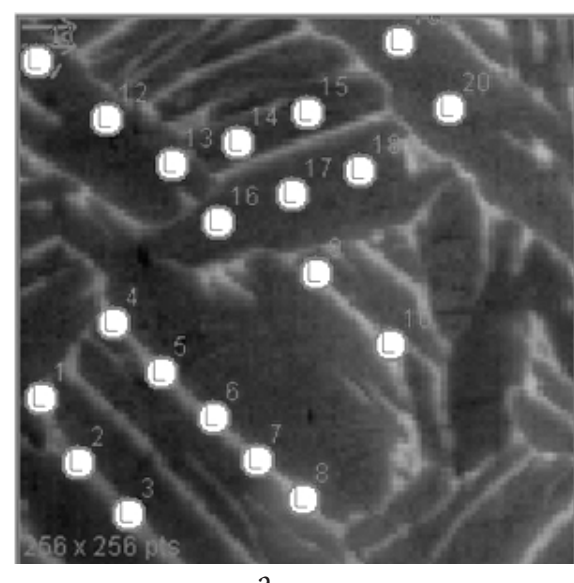

a

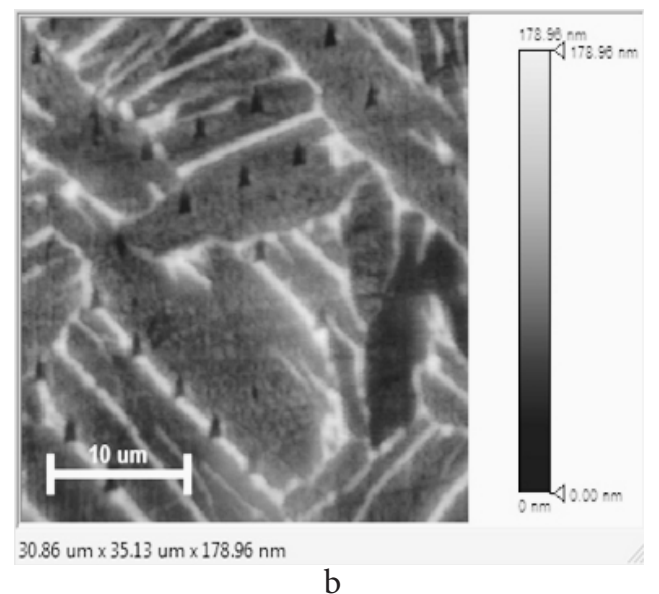

b

Fig. 3. (a) - a map of indentation of the sample for estimation of the modulus of elasticity in the $\alpha$ - and $\beta$-phases in the Ti-6Al-4V alloy; (b) - sample surface after indentation.

result can be a different volume ratio of $\alpha$ - and $\beta$-phases in the Ti-6Al-4V titanium alloy in different structural states. Indeed, as evidenced by the results of the experiment, the elastic property $\mathrm{E}$ of each phase ( $\alpha$ and $\beta$-phases) considered separately in the Ti-6Al-4V alloy differs significantly (Table 2).

The modulus of elasticity E for the $\alpha$-phase is about $22 \%$ higher than for the $\beta$-phase. Similar results for the Ti-6Al-4V alloy have been recently obtained in the work [12].

The modulus of elasticity was determined on a sample in the CG state (Fig.3). Indentation was performed in 10 points for each phase, where indents $1-10$ are located in the $\beta$-phase and indents $11-20$ are in the $\alpha$-phase. The load was $5 \mathrm{mN}$. The data shown in Fig. 2 and Tables 2 and 3 indicate the existing dependence - the larger is volume fraction of the $\alpha$-phase in the Ti-6Al-4V alloy, the higher is the normal modulus of elasticity.

\section{Conclusions}

As result of studying the elastic properties of the Ti-6Al-4V alloy, the following has been revealed:

1) The structural evolution in the Ti-6Al-4V alloy from the NS to CG states promotes a decrease in the modulus of elasticity E by more than $20 \%$.

2) The modulus $E$ for the $\alpha$-phase in the $\beta$-field of the annealed Ti-6Al-4V alloy is significantly (by $22 \%$ ) higher than for the $\beta$-phase.

3) One of the main causes for the variation of the elastic modulus E for the two-phase titanium alloy Ti-6Al-4V may be changes in the volume fraction of $\alpha$-phase.

\section{References}

1. A. P. Gulyaev. Metallovedenie. M., Metallurgiya. (1966) 482 p. (in Russian)

2. V.S. Zolotorevskiy. Mekhanicheskie svoistva metallov. M., Metallurgiya. (1983) 352 p. (in Russian)

3. R.R. Mulyukov. Rossiyskiye nanotechnologii. 2 (7-8), 38-53 (2007). (in Russian)

4. G. A. Salishev, S.V. Zherebtsov, S.P. Malysheva, A. M. Smyslov, E. V. Safin, S. P. Pavlinich., N. F. Izmailova. Titan. 2, 49-52 (2007). (in Russian)

5. A. A. Kruglov, R. Ya.Lutfullin. Problemymashinostroeniya i nadezhnosti mashin. 1, 69-72 (2009). (in Russian)

6. O.R. Valiakhmetov, R.M. Galeev, V.A. Ivanko R. M. Imayev, A. A. Inozemtzev N.L. Kok sharov, A.A. Kruglov, R. Ya. Lutfullin, R. R. Mulyukov, A.A. Nazarov, R. V. Safiulin, S.A. Harin. Rossiyskie nanotekhnologii. 5 (1-2), 12-111 (2010). (in Russian)

7. A. A. Kruglov, O. A. Rudenko. Letters on materials. 2 (2), 107-110 (2012). (in Russian)

8. N. I. Noskova, R. R. Mulyukov. Submicrocristallicheskiye i nanocristallicheskiye metally i splavy. Ekaterinburg. UrO RAN (2003) 279 p. (in Russian)

9. D.I. Ryzhenkov, V.V. Lyovina, E.L. Dzidziguri. Nanomaterialy: uchebnoe posobiye. M. BINOM (2008) 365 p. (in Russian)

10. W.C. Oliver and G.M. Pharr. Journal of Materials Research. 7, 1564-1583 (1992).

11. I. Sen, U. Ramamurty. Scripta Materialia. 62, 37-40 (2010). 